\title{
Determination of the pKa Value of Phenolphthalein by Means of Absorbance Measurements
}

\author{
Manuel Alonso, Sebastián P. Chapela, María L. Cristaldo, \\ Inés Nievas, Hilda I. Burgos Oliver Gamondi, Carlos A. Stella
}

Departamento de Bioquímica Humana, Facultad de Medicina, Universidad de Buenos Aires, Paraguay 2155 Piso 5, 1121 Buenos Aires, Argentina.

Email: cstella@fmed.uba.ar

Received July 23 ${ }^{\text {rd }}$, 2010; revised August $11^{\text {th }}, 2010$; accepted August $27^{\text {th }}, 2010$.

\begin{abstract}
We here report a laboratory protocol for the determination of the pKa value of an acid by means of determinations obtained with a spectrophotometer. Students determine the acidity constant $(K a)$ and the pKa associated with phenolphthalein from the absorbance values obtained from phenolphthalein solutions at different pHs. The present protocol for the determination of the $\mathrm{pKa}$ takes a very short time and is useful when teaching in conditions with limited equipment.
\end{abstract}

Keywords: Medical Science Teaching

\section{Introduction}

Knowing the acidity constant value (Ka) [1] of an acid and its associated pKa value is important for a medical student for different reasons.

One of these reasons is that the pKa of a drug allows obtaining its values of absorption, bioreactivity and tissular accumulation as a function of the $\mathrm{pH}$ of the medium [2].

Another reason is that the pKa values of the amino acids of a polypeptide chain are related to the function and structure of the protein [3]. In addition, the pKa values of different chemical species account for their tubular reabsorption if they are eliminated through the urine [4]. They also allow the understanding and management of the internal medium of a living system [4,5], which can be useful in the diagnosis or treatment of diseases.

Despite the importance of Ka and pKa, many students of Biology or Health Sciences learn about them only through lectures or exercises.

Previous studies [6] have shown that students are usually not able to identify examples or topics that arouse their interest. They have a poor qualitative management of the aspects of chemical balance, probably because today's teaching insists on an operational view of the concept [6]. Many students are not able to infer that the constant depends on the temperature and most of them believe that the constant depend on the concentration of the substances $[6,7]$.

We believe that if the student could empirically determine the Ka value and thus the pKa of a substance, he / she could better understand the basis of the acid-base equilibrium and thus have a more open-minded criterion about its application in practical situations.

The pKa of a certain chemical species can be empirically determined using the potentiometric technique by measuring the $\mathrm{pH}$ value in a titration until it remains constant $[8,9]$. However, both the titration and measurement of the $\mathrm{pH}$ are difficult because they take a relatively long time, and courses in our University have too many students and the equipment is usually not enough for all the students.

For this reason, we have designed a practical way to determine the $\mathrm{pKa}$, which requires only the use of a spectrophotometer or photocolorimeter. The main advantages of this technique are that it is sensitive, takes a short time, and the equipments are both inexpensive and user-friendly.

While there have been several experimental articles published in education papers applying spectroscopy to determine the pKa of acid-base indicators [10,11], the present article addresses the question of how to give stu- 
dents laboratory experience with limited equipment and space.

In the protocol here presented, the student can determine the acidity constant (Ka) of phenolphthalein and its associated pKa from absorbance values obtained from solutions of this substance.

\section{Theoretical Basis}

The student must first know that the acid-base indicators present different colors according to the $\mathrm{pH}$ of the medium. In the case of phenolphthalein, which is a weak acid, its non-disassociated form has no color, whereas its ionized form, or conjugate base, absorbs light at a wavelength of $550 \mathrm{~nm}$.

The theoretical foundation (1) is based on the definition of the acidity constant:

$$
\mathrm{Ka}=\left[H^{+}\right] x\left[A^{-}\right] /[H A]
$$

where $[H A]$ represents the concentration of the non-disassociated acid, $\left[A^{-}\right]$the concentration of its conjugated base, and $\left[\mathrm{H}^{+}\right]$the concentration of protons.

In a strongly basic medium, most of the $H A$ is as an $A^{-}$ anion because the concentration of non-disassociated acid is much lower:

$$
[H A] \text { total }=\left[A^{-}\right]^{\boldsymbol{b}}
$$

The supra-index " $\boldsymbol{b}$ " accounts for the alkalinity of the medium.

In conditions in which the non-disassociated acid concentration is not negligible, the acid ([HA] total) will be present in both its dissociated and non-disassociated forms.

Taking Equation (2) into account, we can state that:

$$
\left[A^{-}\right]^{\boldsymbol{b}}=[H A]+\left[A^{-}\right]
$$

By Lambert-Beer Law, the Absorbance ( $A b s$ ) of a solution is related to the concentration as follows:

$$
A b s=\alpha \times b \times\left[A^{-}\right]
$$

where

$\alpha=$ coefficient of molar absorption,

$b=$ the distance traveled by the light beam.

Taking Equation (3) into consideration:

$$
[A-]^{b}-\left[A^{-}\right]=[H A]
$$

And then, by replacing (5) in (1), we obtain:

$$
K a=\left[H^{+}\right] x\left[A^{-}\right] /\left[A^{-}\right]^{b}-\left[A^{-}\right]
$$

Considering Equation (4)

$$
K a=\left[H^{+}\right] x(A b s / \alpha x b) /\left(A b s^{b} / \alpha x b-A b s / \alpha x b\right)
$$

Then, by removing the common factor $\alpha x b$ and simplifying the equation, we obtain:

$$
K a=\left[H^{+}\right] x A b s /\left(A b s^{b}-A b s\right)
$$

Clearing $\left[H^{+}\right]$, we have:

$$
\left[H^{+}\right]=K a x\left(A b s^{b} / A b s-1\right)
$$

Finally, by removing the parenthesis:

$$
\left[H^{+}\right]=K a \times A b s^{b} / A b s-K a
$$

This equation is similar to that of a straight line of the following form:

where:

$$
y=a+b x
$$

$$
\begin{gathered}
y=\left[H^{+}\right] \\
b=K a \times A b s^{b} \\
x=1 / A b s \\
a=K a
\end{gathered}
$$

\section{Development}

The assays to carry out this protocol require $2 \mathrm{~h}$ at the laboratory.

Before performing the dilutions or the absorbance reading, the laboratory instructor should explain the basis of the determination.

Instructor's activity: the laboratory instructor should prepare six solutions of $\mathrm{Na}_{2} \mathrm{HPO}_{4}(\mathrm{Mr}=142) 100 \mathrm{mM}$ with different values of $\mathrm{pH}$. The solutions must be prepared from this mother solution and then add $\mathrm{PO}_{4}^{-3}$ $\mathrm{NaOH}$ or $\mathrm{HCl}$, as indicated in Table 1.

Each student then receives $10 \mathrm{ml}$ of the solutions 1 to 6 .

In addition, the instructor should prepare a phenolphthalein solution $1 \%$ in ethanol and dilutes a $200-\mu \mathrm{l}$ aliquot in $10 \mathrm{ml}$ water. Each student receives $6 \mathrm{ml}$ of this dilution.

Student's activity: each student or group of students mixes $10 \mathrm{ml}$ of each phosphate solution with $1 \mathrm{ml}$ of the diluted phenolphthalein solution. These six new solutions must be denominated as A, B, C, D, E and F. The absorbance of the solutions is read at $550 \mathrm{~nm}$ in a spectrophotometer or photocolorimeter. The student will then record the values obtained and the $\mathrm{pH}$ value for each solution in a table.

Table 1. Solutions with different $\mathrm{pH}$ that the laboratory instructor should prepare.

\begin{tabular}{cccc}
\hline Solution & $\begin{array}{c}\text { Volume of NaOH } \\
1 \text { M every 10 ml of } \\
\text { phosphate }(\mu \mathrm{l})\end{array}$ & $\begin{array}{c}\text { Volume of HC (c) } \\
\text { every 10 ml of } \\
\text { phosphate }(\mu \mathrm{l})\end{array}$ & $\begin{array}{c}\text { pH value } \\
\text { obtained }\end{array}$ \\
\hline 1 & 40 & --- & 9.36 \\
2 & 10 & --- & 9.23 \\
3 & --- & --- & 9.15 \\
4 & --- & 10 & 8.87 \\
5 & --- & 20 & 8.73 \\
6 & --- & 30 & 8.56 \\
\hline
\end{tabular}




\section{Results}

After measuring the absorbance of the A, B, C, D, E and $F$ solutions, the values of " $y$ " and " $x$ " should also be recorded and calculated. The values of a representative assay we carried out are presented in Table 2. Figure 1 shows a graphic representation of the values of Table 2.

After that, "a" (the point at which the line crosses the $y$ axis) is calculated in the two following possible ways:

a) graphically, by drawing the straight line manually in a millimeter paper and making the line as close as possible to all the points. With this procedure, the Ka showed values of $2.75^{-10}$ and $3.25^{-10}$, which represented values of 9.6 and 9.5 respectively.

b) by adjusting the data with the program Origin ${ }^{\circledR}$ (version 6.0). This procedure yielded a Ka $=4.657^{-10}( \pm$ $1.132^{-10}$ ), which corresponds to a pKa value of $9.3 \pm 0.1$. It must be pointed out that the pKa accepted for phenolphtalein at $25^{\circ} \mathrm{C}$ is 9,7 [12].

Table 2. Absorbance (Abs) values of the indicator solutions at different pHs.

\begin{tabular}{cccc}
\hline \multicolumn{4}{c}{ Representative assay. } \\
Solution & $\mathrm{y}=\left[\mathrm{H}^{+}\right]$ & Abs & $\mathrm{x}=1 / \mathrm{Abs}$ \\
\hline $\mathrm{A}$ & $4.3610^{-10}$ & 0.411 & 2.433 \\
$\mathrm{~B}$ & $5.8910^{-10}$ & 0.306 & 3.268 \\
$\mathrm{C}$ & $7.0810^{-10}$ & 0.270 & 3.704 \\
$\mathrm{D}$ & $1.3510^{-9}$ & 0.109 & 9.174 \\
$\mathrm{E}$ & $1.8610^{-9}$ & 0.041 & 24.390 \\
$\mathrm{~F}$ & $2.7510^{-9}$ & 0.026 & 38.462 \\
\hline
\end{tabular}

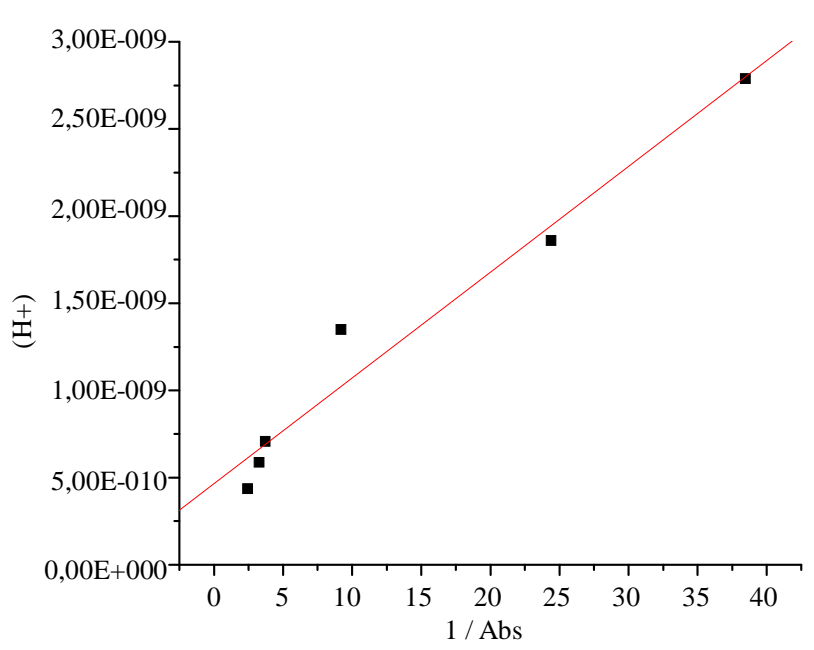

Figure 1. Graphic representation of the absorbance values of the indicator solutions at different pHs. The ordinate indicates the $\left[\mathrm{H}^{+}\right]$from which the $\mathrm{pKa}$ is calculated according to Equation (9).

\section{Conclusions}

This protocol allows students to determine the pKa value of phenolphthalein in a short time and without using the potentiometric method. It thus has the advantage that, in a laboratory where a spectrophotometer or photocolorimeter are available, a large number of students can carry out the determination at the same time. As we mentioned in Introduction there are many good procedures but may not be useful for large classes with limited equipment.

This makes it easier to develop the activity, especially because the use of a potentiometric method requires numerous $\mathrm{pH}$-meters, takes a long time and depends on the ability of the students. In addition, the laboratory instructor is able to show the application of the Lambert-Beer Law for acid-base indicators in which the forms have different coloration according to the $\mathrm{pH}$ of the medium.

This strategy for the determination of the pKa can also be used to discuss the case of other chemical species in which the non-ionized form has color [13]. In such case, the contribution of the color of the other form of the weak acid should be subtracted from the absorbance measured in Table 2.

\section{REFERENCES}

[1] P. Atkins and L. Jones, "Principios de Química, los Caminos del Descubrimiento,” Panamericana, Buenos Aires, 2005.

[2] L. L. Brunton, J. S Lazo and K. L. Parker, "Las Bases Farmacológicas de la Terapéutica,” McGraw Hill, España, 2006.

[3] L. Stryer et al., “Bioquímica,” Reverté, Barcelona, España, 2003.

[4] A. C. Guyton, “Tratado de Fisiología Médica,” Elsevier, España, 2006.

[5] T. Devlin, “Bioquímica,” Reverté, Barcelona, España, 2003.

[6] H. Moncaleano, C. Furió, J. Hernández and M. L. Calatayud, “Comprensión del Equilibrio Químico y Dificultades en su Aprendizaje, Enseñanza de las Ciencias,” Número Extra, 2003, pp. 111-118.

[7] L. Viennot, "Raisonnement a Plusieurs Variables: Tendances de la Penseé Commune,” Aster, Vol. 14, No. 1, 1992, pp. 127-141.

[8] B. N. Blanchette, and B. R. Singh, "A Single Protein Research Integrated Advanced Biochemistry Laboratory Course; Spectroscopic Determination of Tyrosyl Side Chain pKa," Biochemical Education, Vol. 28, No. 2, 2000, pp. 107-109.

[9] P. L. Alvarado, J. C. Menéndez and M. T. Ramos, "Medida del pKa de Varios Fenoles y su Aplicación a la Determinación de Parámetros Electrónicos,” 2006. 
http://www.iupac.org/publications/cd/medicinal_chemistr y/Practica-III-5.pdf

[10] G. S. Patterson, "A Simplified Method for Finding the pKa of an Acid-Base Indicator by Spectrophotometry," Journal of Chemcal Education, Vol. 76, No. 3, 1999, pp. 395.

[11] K. P. Alter, J. L. Molloy and E. D. Niemeyer, "Spectrophotometric Determination of the Dissociation Constant of an Acid-Base Indicator Using a Mathematical Deconvolution Technique,” Journal of Chemistry Education, Vol. 82, No. 11, 2005, pp. 1682-1685.

[12] “The Merck Index,” 13th Edition, Merck \& Co., Inc., New Jersey, 2001.

[13] S. W. Tobey, "The Acid Dissociation Constant of Methyl Red,” Journal of Chemistry Education, Vol. 35, No. 13, 1958, pp. 514-515. 